\title{
Use of Info-Communicational Resources in Software Systems
}

\author{
Andranik E. Mkhitaryan, Arthur S. Petrosyan and Aram S. Nanassian \\ Institute for Informatics and Automation Problems of NAS RA \\ e-mail: and.mkhitaryan@gmail.com, arthur@sci.am, ananas@sci.am
}

\begin{abstract}
The use of info-communicational resources in software systems is considered. The integration details and mechanisms of info-communicational resource UniMail into other systems are considered. Examples of software systems types, which could use the services of UniMail resource are discussed.
\end{abstract}

Keywords: Notification, Alert, E-mail, SMS.

\section{Introduction}

Nowadays, the creation of software systems considers the use of many different independent modules. Each of the modules has its own part of work to complete. This helps to economize the resources by sharing them and the time that would be spent for implementation of all components by using already implemented items. All software systems, which should send notifications by any network should have an info-communicational module. Such systems are being used to pass messages from one resource to another. The most popular infocommunicational platforms are based on the Internet, GSM, etc., networks. The software could be designed by different ways depending on the requirements. The component could be either embedded or independent. Each variation has specific advantages and disadvantages, which should be considered in the architecture of the software.

\section{Solution}

The module responsible for sending operative notifications is one of the most important and common components of software systems. The module could be either embedded or separated. Nowadays, both techniques are widespread because of their specific advantages. 
The embedded case considers that the system has its own software and hardware equipment. For instance, a connection to GSM network requires GSM modem and the appropriate software component. For such cases the module is being used only for that system (Figure 1). One of the advantages of this structure is that the system is able to fully control the module's resources because it is the component's only client.

Such technique is preferable in case the module is used intensively on heavy load by the system. Sharing its resources could lead to critical health issues and timeouts. The other advantage is that the implementation will be more specific to the software needs because it is not mandatory for the module to be generic.

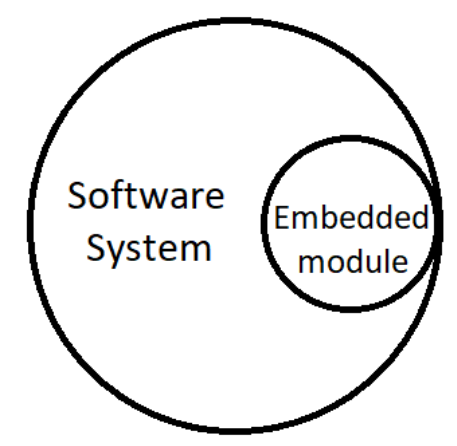

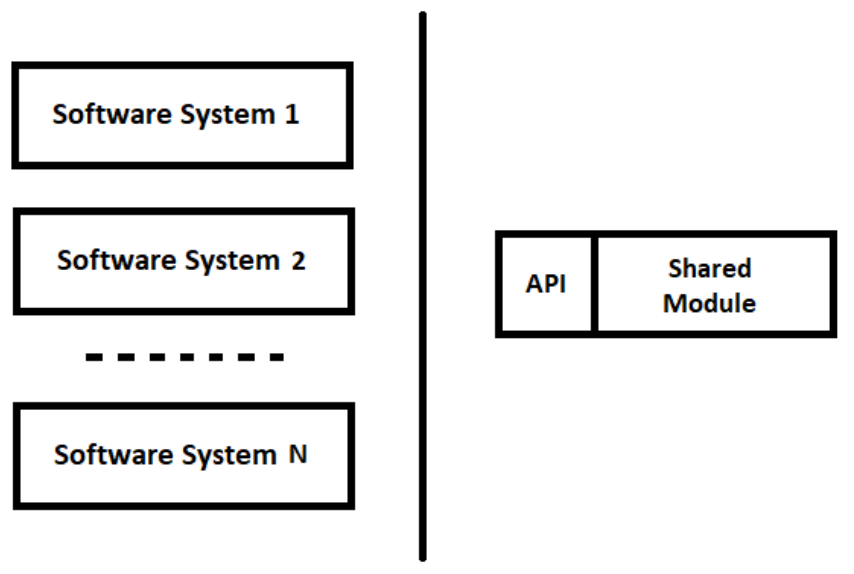

Fig. 2. Independent components of software system.

The other technique is about to usage of independent modules in common inn case of possibility. For this type of systems some of the resources will be shared with other clients. On this concept the module is a detached and self-determined resource, which provides already defined public application programming interface (API) to access the listed by itself functionality. Each permitted software system has an ability to access and use the functionalities provided by the component. Such systems are much more economical than the above described one. The main advantage is that the software and hardware of the module are being shared by many applications with API. The module can serve as many clients as its equipment allows.

UniMail is a software system, which provides info-communicational services [1],[2]. The system is connected to both Internet and GSM networks. UniMail is able to send SMS messages to the mobile phone subscribers by GSM network. It provides a public interface to access the available services. As a public interface it uses email technology. There is a specified list of commands to configure and use the provided services. In general, Animal could act as a notification module for other systems. Usually, the same information is being sent by e-mail and by SMS. For such cases UniMail services become much more practical. The user just needs to add some additional configurations during the email message preparation process. The integration of UniMail is suitable for any type of software.

Some corresponding commands of UniMail with descriptions:

$>*<$ phone number(s) $>*$ command in subject sending to more than one email addresses - Parallel to the letter send SMS notification to the addressee(s)

$>*<$ phone numbers $>*$ command in subject and sending to the UniMail's email address only - Send an SMS to the addressee(s)

Here are some examples of systems, which could use its services. 


\subsection{Monitoring Systems}

Monitoring systems are a typical example of a complex software system. They have their important role in stability and health of other software resources. Such systems are being used for analyzing the state of the resource (i.e., web server) and reporting about the critical issues. The reporting part of systems is based on the info-communicational mechanisms, such as e-mail, SMS, Internet, etc. Nowadays, one of the widespread mechanisms of info-communication is SMS. The undeniable advantage of this mechanism is that the messages are

To administrator@example.com $\times$
Cc unimail (unimail.asnet.am) $\times$
Alert *<admin's phone number ${ }^{*}$
$\mathrm{Hi}$,
Detected "network issue on mail server*.
Please resolve it as soon as possible.

Fig. 3. Format of E-mail components. being directly delivered to the addressee, which is very important for monitoring systems. Usually in emergency situations a quick action should be taken to avoid further problems, thus the responsible stuff should be aware about the issues as soon as possible. UniMail could be used for sending operative notifications by SMS messages. In such systems usually e-mail and SMS messages are used for alerting. In case the emailing mechanism is already configured, the minimal effort will be required to send an SMS notification as well (Figure 3).

UniMail is a part of monitoring process of a mail server at the Institute for Informatics and Automation

Problems of NAS RA. There are types of issues, which affect critically the workflow of the server, i.e., network or queue size related problems [5].

- Network related issues are one of the most critical categories of problems that could appear on mail servers. In such cases the server could become unavailable for users and other mail providers.

- Another category of issues is related to the queue of e-mails. As a result of attack one or more accounts of a mail provider could be hacked. The next step of such attacks is sending spam messages to mail addresses of other providers (Sum-outbreaking issues). Well-known mail providers like Gmail, Yahoo will block the mail account, from which lots of spam e-mails are being received as well as the mail provider. Such issues should be detected and resolved as soon as possible. Otherwise, e-mails sent from the accounts of that provider will be considered as a spam and will not be received by the addressee.

There is a deployed application on the mail provider's server, which is periodically checking for network connectivity and sum-outbreaking issues. If any issue has been detected, the application combines an email message with the corresponding content (Figure 3) and sends it to the admin's and UniMail's addresses. Then the administrator will receive both e-mail and SMS alerts.

In case the UniMail server and mail server are located at the same local network the aroused issues will be reported even if there are connection problems with global network. In this case the email message could not be sent as mail providers communicate p2p by the Internet protocols. However, the SMS alert will be delivered because it is transmitted through GSM, which is a completely different communicational network. 


\subsection{Authentication Module}

SMS technology leaves its footprint on the authentication process of the multiuser services. For most known multiuser services, the user should be registered and authenticated by phone number (or by email address, but most probably, the user has been authenticated by phone number during the creation of mail account). To be able to identify the person with his phone number an SMS message with randomly generated verification code is being sent to him. The code should be reentered into the system, where the user is trying to register, then the system compares and checks the correctness of the sent (by SMS) and entered (by user) codes. UniMail as an infocommunicational resource could make the registration process of multiuser applications easier. Any permitted app could send an SMS message with verification code to the user by email interface.

A similar technique is being used for password resetting process of already registered users. Some systems require users to get verified by phone number, which they used for registration to permit password change. This way they prevent unauthorized users (i.e., hackers) who somehow could access the account, change the password. A similar code being generated by UniMail as an info-communicational resource could make the registration and password reset processes of multiuser applications easier. Any permitted app could send an SMS message with a verification code to the user via email interface.

\section{Conclusion}

The applications, which need to send messages by GSM network are required to have a module for it. In general, the module could be either embedded or separated. Separated module is more economical taking into account resources and time. For complex software systems the UniMail resource can serve as an info-communicational module. It is providing an easy to use public interface by email technology. The use of UniMail can make the creation process of systems easier, which needs to get to GSM network and send operative SMS messages.

\section{References}

[1] Д. Геворкян, А. Нанасян и К. Хачатрян «Новые WEB ресурсы ASNET.AM», Материальк конф. СSIT-2011, Ереван, сс. 311-313, 2011.

[2] D. Gevorkyan, K. Khachatryan, A. Nanassian, A. Petrosyan, G. Petrosyan, V. Sahakyan and E. Vardanyan, "Mail informer- selective incoming instand phone notification system”, Proceedings of International Conference Computer Science and Information Technologies, CSIT, Yerevan, Armenia, pp. 466-- 467, 2009.

[3] А. Нанасян и К. Хачатрян, «Mail2sms.asnet.am - система оповещения о входящих письмах», Материальл конф. СSIT-2013. Ереван, 2013.

[4] E. Mateev, A. Mkhitaryan, A. Nanasyan, V. Sahakyan and A. Petrosyan, “Hybrid infocommunication Email SMS UNImail system”, Proceedings of International Conference Computer Science and Information Technologies, Yerevan, Armenia, pp. 389-- 391, 2009.

[5] Natale Maria Bianchi, “A Survival Guide for the Small Mail Server” Spamhaus 2015. 
Submitted 20.07.2018, accepted 02.12.2018.

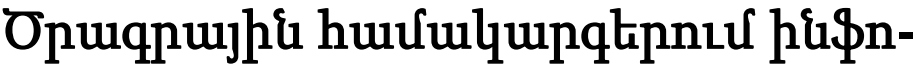

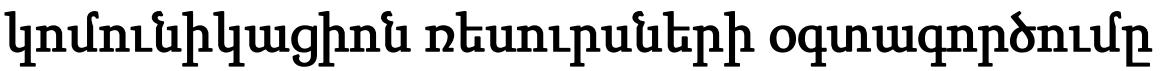

U. Uhuppunjuid, U. Thinpnujuid li U. ¿uiduujuid

\section{Uựนnนุhnư}

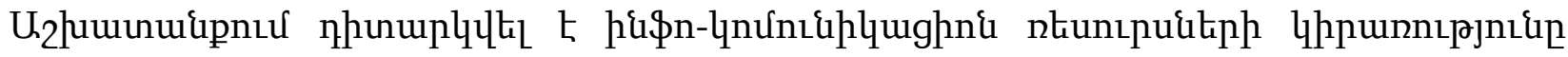

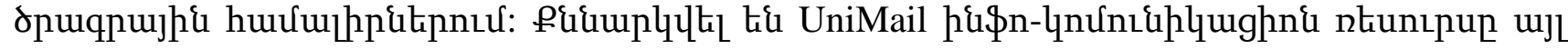

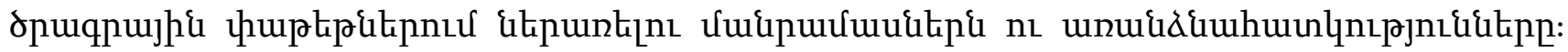

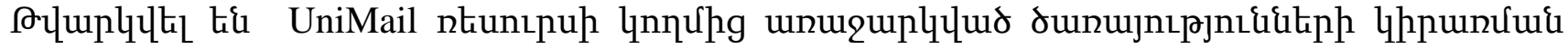
ophiuulitip:

\section{Использование информационно- коммуникационных ресурсов в программных системах}

\author{
А. Мхитарян, А. Петросян и А. Нанасян
}

\begin{abstract}
Аннотация
Рассмотрено использование информационно-коммуникационных ресурсов в программных системах. Рассмотрены детали и механизмы интеграции информационно-коммуникативного ресурса UniMail в других системах. Обсуждаются примеры типов программных систем, которые могут использовать сервисы ресурса UniMail.
\end{abstract}

